\title{
Synergy of pluralism - an urban form in the modern housing environment
}

\author{
Wojciech Januszewski ${ }^{1, *}$ \\ ${ }^{1}$ Wrocław University of Science and Technology, Faculty of Architecture, ul. Prusa 53/55, 50-317 \\ Wrocław, Poland
}

\begin{abstract}
The present text aims to outline current contemporary formal trends in housing urban planning on the examples of characteristic realizations of recent decades. The paradigm of contemporary urbanism is the sustainable urban planning. The idea is usually interpreted in the spirit of the so-called compact city. This, however, allows for a variety of formal interpretations. A characteristic feature of contemporary urban planning is the lack of doctrinal formal assumptions. The formulation of general principles is avoided, and the proposed solutions are of individual nature. The form becomes a means of artistic expression and spatial articulation rather than a carrier of a social idea. It is also a tool for positioning the complex as a product in the market game. The study covers the problems of new phenemomena such as transformations of the urban block, functional hybrids and hybrids of nature and urbanity.
\end{abstract}

\section{Introduction}

The urban form is a method of organizing the space of human life. The present text aims to outline current contemporary formal trends in housing urban planning on the examples of characteristic realizations of recent decades.
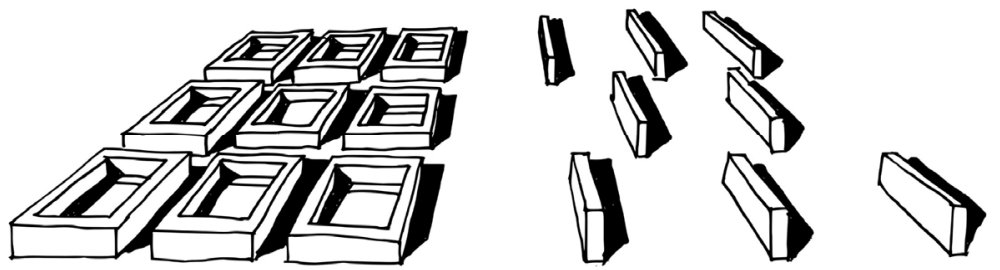

Fig. 1. The two models of urban space - traditional/postmodern (left) and modernist (right). Author's drawing.

A synthetic description of urban planning of the beginning of the 21 st century is difficult in comparison to earlier periods, in which one can precisely indicate the directions of evolution. In early and mature modernism, such a trend was to strive for the loosening of urban fabric - as a reaction to the problems of the 19th century. In late modernism and

* Corresponding author: wojciech.januszewski@pwr.edu.pl 
postmodernism, the leading motive was to search for defined spaces of social significance and to restore the developmental continuity of cities. These directions were expressed in specific formal solutions - in the first phase, in the gradual resignation from a closed block, in the second phase - in its restoration [1]. The culmination of the modernist phase falls in the mid-1950s, the postmodern one - in the late 1980s and early 1990s, which was reflected in two Berlin exhibitions - Interbau 1957 and IBA 1987 (Fig. 1.).

The paradigm of present day is the sustainable urban planning. This idea is usually interpreted in the spirit of the so-called compact city [2]. The compact city is concentrated and strongly internally connected by a dense street network. Thus, the modernist superblock concept is abandoned; the "molecular" urbanism is rather the preference. An important demand related to land saving is the densification of buildings. The above postulates, however, allow for a variety of formal interpretations. Below are selected tendencies in shaping the urban form.

\section{Transformations of the urban block}

Although the urban block has again become the main structural unit, it does not have to be a closed peripheral block. Although the movement of new urbanism is still alive, the influence of neo-traditionalism has clearly decreased over the last decades. Already at the turn of the 1980s and 1990s, the Dutch architectural avant-garde, represented by OMA, MVRDV, and Mecanoo, questioned its indivisible rule and based their experiments on modernist models [3]. Today, forms with different historical genesis are freely used. Contemporary urban planning in the polemic about "a free-standing form or perimeter buildings" takes an intermediate position. New, experimental typologies are also being created.

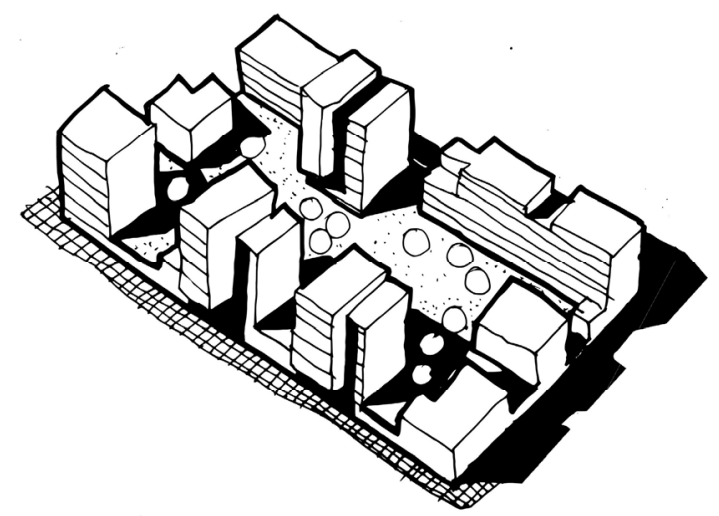

Fig. 2. The open block by Christian de Portzamparc (Le Tripode, Nantes, 2012). Author's drawing.

In the 1980s, Christian de Portzamparc popularized the concept of an 'open block' as an alternative to a closed block and freestanding buildings. Portzamparc drew attention to the disadvantages of both models, which preclude their massive use. The closed block creates a claustrophobic inner space of courtyards, prevents access to sunlight and proper ventilation of buildings. In turn, the open composition eliminates the category of the street, making the urban space irregular and anonymous. The modern city needs both openness and clear public spaces. According to Portzamparc, the solution is an 'open block', consisting of separate buildings, located along the street frontages. The block maintains the integrity of semi-public interiors and public space while ensuring views, ventilation, andisolation (Fig. 2.). The Portzamparc concept - consciously or not - is often used in urban planning today [4]. 


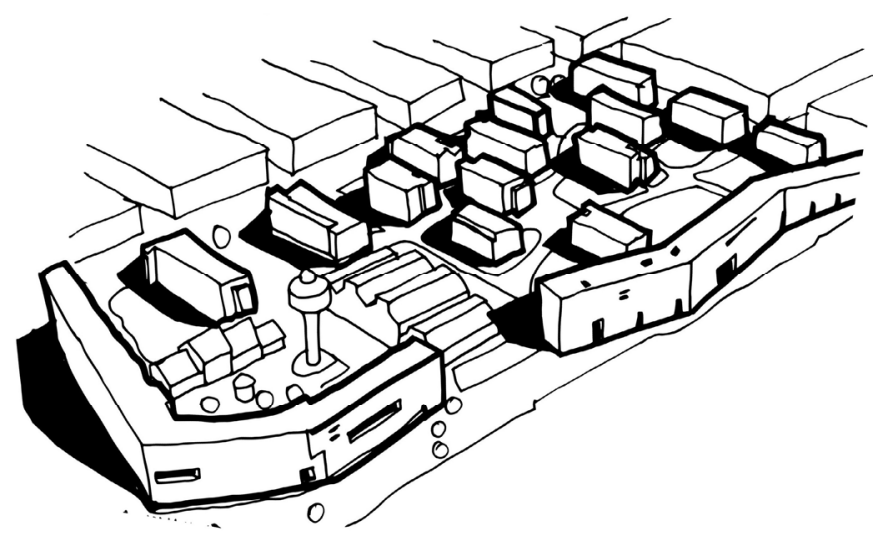

Fig. 3. GWL Terrein housing in Amsterdam (completed 1998). Author's drawing.

Another method of combining two urban principles is presented by the GWL Terrein residential complex in Amsterdam. It was built in the former headquarters of the municipal water supply company (GWL) according to the design of KCAP of Kees Christiaanse. From the west and north, the area is surrounded by a meandering slab building, which rises to the height of 4-9 floors. This elongated structure contains about $57 \%$ of apartments and is the boundary between the residential area and the adjacent industrial area. It also protects the area from the west wind and the noise of car artery. In the urban space defined in such a way, 14 residential buildings from four to five floors high are located, free-standing on green islands of private gardens surrounded by hedges. Several historic buildings were preserved, including the water tower which emphasizes the former function of the area and is an architectural dominant. The interior of the unit is completely car-free. The complex combines the solutions of a closed peripheral block with an open composition typical of the urbanism of functionalism (Fig. 3.).

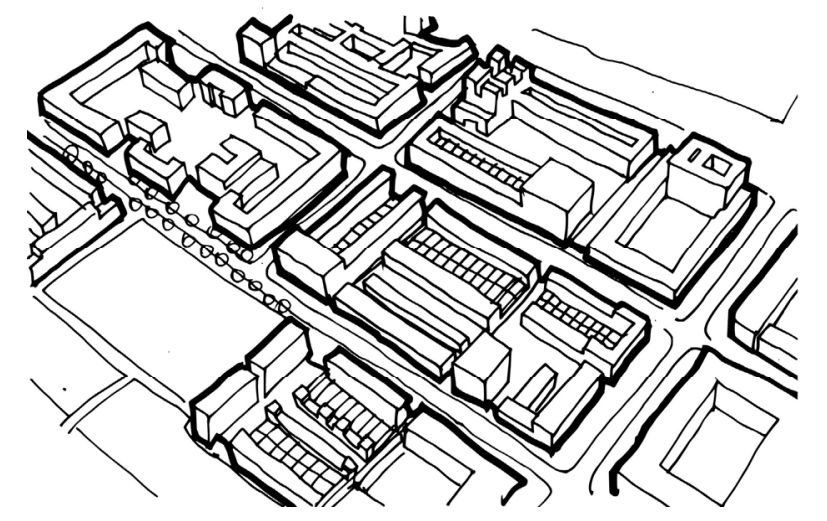

Fig. 4. Ijburg district in Amsterdam (fragment). A variety of block typologies. Author's drawing.

An interesting strategy for transforming the perimeter block was used in the design of the Jjburg district of Amsterdam. The estate was built on artificial islands of $\mathrm{Ij}$ Lake according to the design of Felix Claus, Frits van Dongen, and Ton Schaap team in 2000-2012. The spatial layout of the complex is based on an orthogonal network of traditional streets defining regular quarters with dimensions of approximately $200 \times 90 \mathrm{~m}$. Individual quarters were realized by separate design teams, following the master plan guidelines. The plan imposed a limitation on the height of buildings and the location of 
buildings around the circumference of the quarters. However, the requirements for the size of the functional program for every quarter exceeded the potential of an ordinary peripheral block. Three transformation strategies could be applied according to the masterplan: 1) extension of the circuit - folding, an addition of internal streets and squares peripherally surrounded, etc.; 2) widening the route, e.g. by introducing annex buildings; 3) matrix using the entire block surface for high-density atrium development, e.g. illuminated by internal patios. The effect achieved thanks to this strategy is a big diversity of living space while maintaining a consistent composition of public space (Fig. 4.).

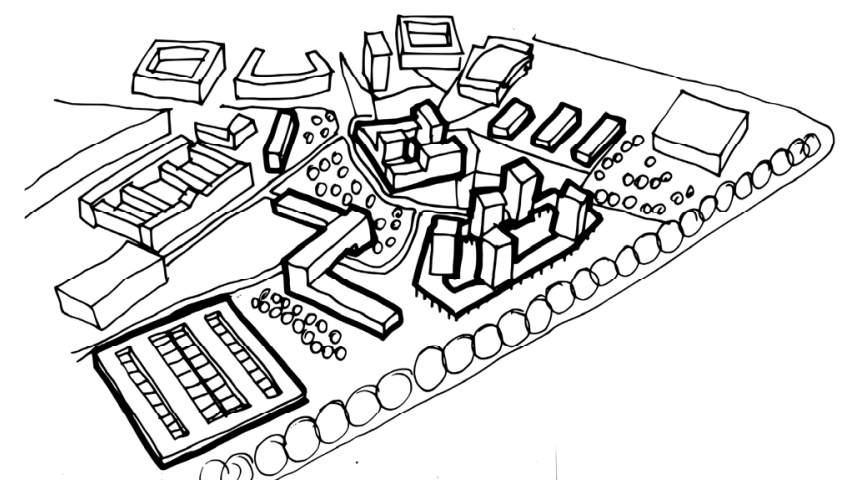

Fig. 5. Chasse Campus in Breda (Netherlands, completed 2000). Author's drawing.

An example of radical formal diversity in urban planning is the Chasse Campus housing complex in Breda. It was erected near the city center on the site of former military barracks (Fig. 5.). The unit has 730 flats of various types, partly dedicated to students. The idea behind the project was "a combination of openness and urbanity". The urban layout designed by Rem Koolhaas introduces a completely free composition of autonomous elements with diverse typologies. The complex consists of 12-story tower houses, a closed peripheral quarter, a line-building unit, a low-rise and high-density atrium building complex, and a Z-shaped residential building creating a gate form for the meandering shared zone street. The whole is supplemented by pre-existing historical buildings.

The designers avoid suggesting any spatial relationships by setting individual elements at different angles. The dynamic drawing of the surface of the square enhances the impression of the system's chaotic nature. According to the intention of the authors, the green is the only unifying value [5].

\section{Functional hybrids}

Various spatial effects are the result of combining housing with other functions. An unusual solution can be found in the plan of the new city center of Almere.

Located in the north-west of the Netherlands, Almere is the youngest city in the Netherlands, built at the end of the 1970s in the area of drained polders around Ijsselmeer. In 1994, OMA studio of Rem Koolhaas won the competition for an urban development project for the downtown district. The greater part of the complex wasn't completed until 2007. Individual objects were erected according to the designs of renowned European architects. The functional program of the new district includes $67,600 \mathrm{sqm}$ of service and commercial space, 9,000 sqm for culture and entertainment (theatre, cinema), and 890 residential units. The solution of communication is an innovative element of the complex - in line with the Dutch tendency to subordinate the public space to the requirements of pedestrian traffic. The layered zoning of functions was adopted as the main 
rule of the unit's organization. The lowest level, hidden under the concrete slab, is intended for vehicle traffic. There is a huge garage with 3300 parking places and an indoor street used for private vehicles and city buses. The upper level is the proper urban space dedicated only to pedestrians. It is organized as a network of interconnected passages distinguished by the frontages of services on the ground floors. Above, there are apartments and office spaces [6].

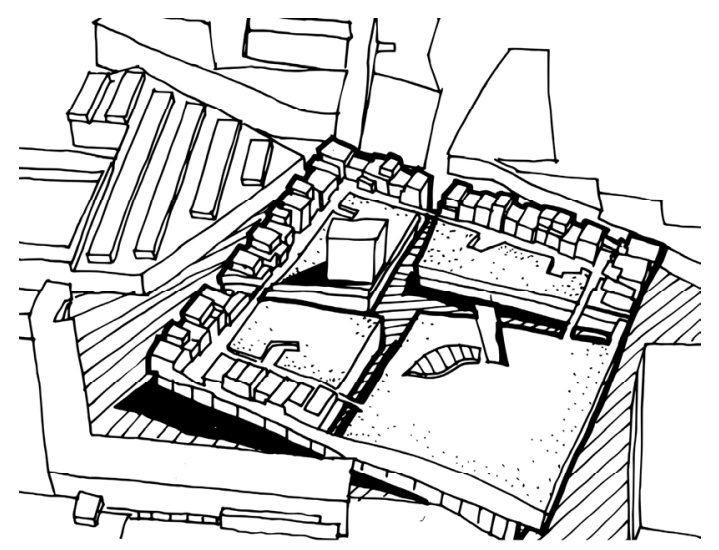

Fig. 6. "Citadel" in the new city center in Almere (Netherlands). Author's drawing.

The element that crystallizes the plan is a multi-functional urban block called the "Citadel", architecturally developed by Christian de Portzamparc. (Fig. 6.) The spatial layout of the Citadel results from the imposition of a form of a turned square on the axis of the main street of the city. The street and two additional side streets cut the Citadel into four irregular parts. Platforms at the roof level and the uniform development of its architecture allow maintaining the impression of consistency of the form. The ground floors and lower floors of the building are entirely intended for commercial services, including shopping malls. The residential function is placed only on the top floor as single-family terraced segments on the perimeter and in the tower house that accents the intersection of inner streets.

The flat roof creates a corrugated surface with extensive greenery. The originality of the solution lies in the fact that the public space is introduced to the heart of the urban block, while the living space is moved to the roof level. The share of the living space in the entire functional program does not exceed $30 \%$.

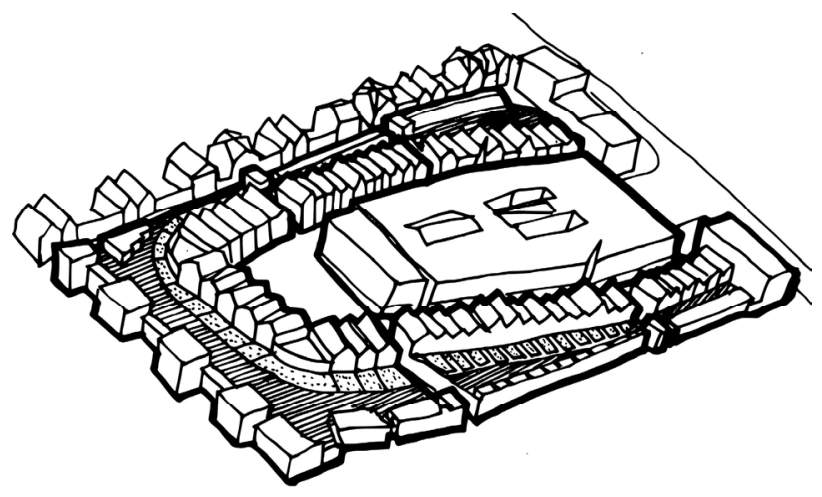

Fig. 7. Housing and shopping complex de Parade in Nootdorp (Netherlands). Author's drawing. 
A similar solution has the Parade complex in Nootdorp in the postmodern stylistic, a project of Sjoerd Soeters and Jos van Eldonk realized in 2003. (Fig. 7.) The complex acts as a new center for the town of Nootdorp in the agglomeration of The Hague and for the extensive Ypenburg housing estate created as part of the VINEX program. The scale and urban form refer to traditional patterns, whereas the functional disposition creates a complicated multi-level layout, subordinated to the vehicle parking organization. A large central block - the "Basilica" - houses a shopping gallery and a multi-story garage for cars. The Basilica is surrounded by the ring of frontages of houses with commercial premises on the ground floor and residential ones above. The wide service tracts form a terrace on the first floor, where a neighbor zone was designed - a semi-public street and semi-private front gardens connected to the apartments. The second outer ring is created of semidetached houses, which are a compositional transition to the extensive development of the suburbs. The main public space is the "market" with shops, gastronomic premises, and a small playground [7].

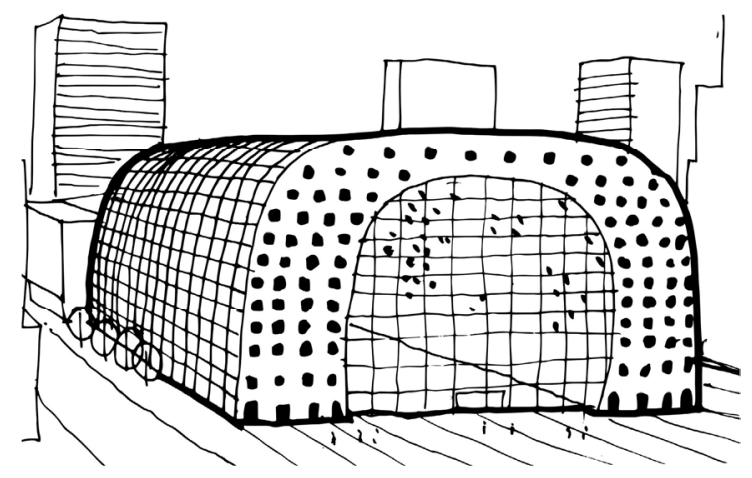

Fig. 8. Market hall in Rotterdam. Author's drawing.

A spectacular example of the combination of residential and commercial functions is the market hall in Rotterdam by MVRDV studio. (Fig. 8.) The building was created as a result of a competition prepared in 2004 by the city authorities for a concept combining apartments and a market hall. It houses 228 apartments with an area of 80 to $300 \mathrm{~m}^{2}$ (half of them for rent), a sales hall, a supermarket, a number of places to eat, and underground garages. The apartments are located in the thickness of the outer monumental mantle constituting the roof for the sales hall. The flats have a view outside and into the inner space through windows or glass floors. The apartments do not have any external living space. From the point of view of a conventional design of housing complexes, these are substandard flats - they do not have access to greenery, playgrounds, semi-public neighborhoods. They are surrounded by the constant noise and traffic of the big city. The popularity of this type of solution proves the changes in the perception of housing environment, primarily about emphasizing the possibility of choosing one's own place of residence in accordance with your preferred lifestyle. This choice, of course, is associated with the acceptance of certain disadvantages and limitations [8].

\section{Hybrids of nature and urbanity}

The examples discussed so far concerned the already mentioned concept of the compact city. It relies on the effective use of urban areas in order to stop the expansion of urban space into natural and agricultural areas. Traditional understanding the essence of urbanization remains: it is the "occupation" of meadows, forests, and fields by the city - the transformation of one category of space into another. An alternative is the idea of the 
combination of nature and urbanization, according to which the elements of an urban functional program are not a separate value from the natural and agricultural landscape but are integrated into it as its integral part. The origins of this approach can be traced back to the concept of Broadacre City by Frank Lloyd Wright based on extremely extensive development associated with agricultural areas. The idea of the city in a landscape - this time extremely intense - guided Le Corbusier in his visions of the complexes of great Unités, e.g. the plan for Meaux [9].

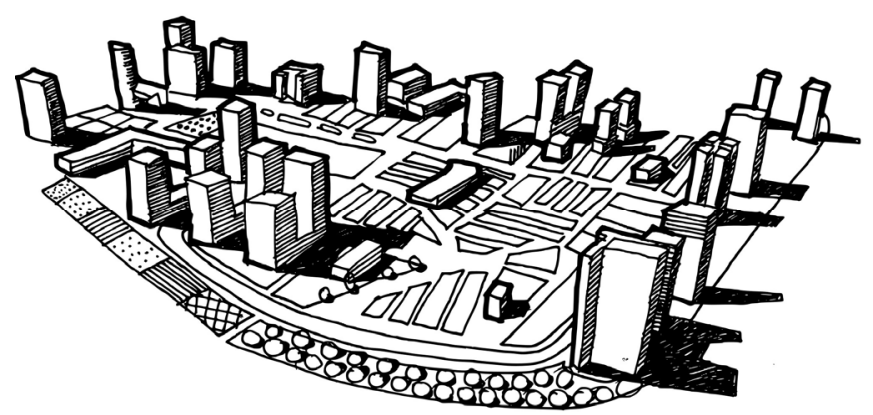

Fig. 9. Sociopolis in Valencia, since 2002. Author's drawing.

Vincent Guallart calls the contemporary variation of this direction a "rurban" - as a hybrid of ruralism and urbanism. Guallart is the author of the Sociopolis project. It was designed in the suburbs of Valencia, in historic gardens irrigated by canals from the Turia River. The project includes over a dozen residential complexes with a rich social services program, designed by world architectural offices. The dominating forms are high tower houses that stand freely among the preserved gardens and fields which are intended to be maintained and grown by the inhabitants themselves [10].

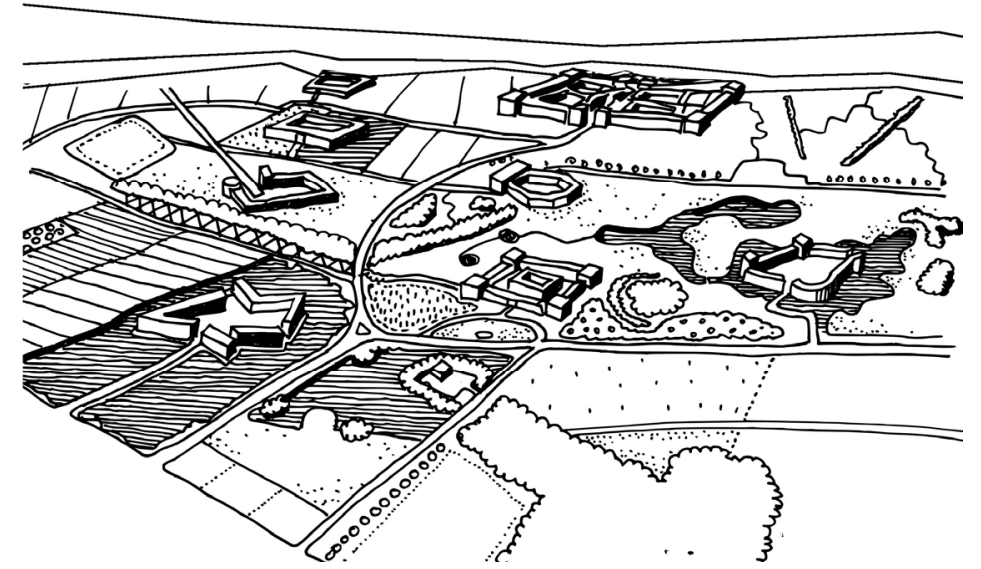

Fig. 10. Haverleij complex in s'-Hertogenbosch (Netherlands, since 2000). Author's drawing.

A similar example may be the Haverleij complex designed by Soeters and Van Eldonk studio in the suburb of the Dutch city of s'-Hertogenbosch. The site covers 160 hectares of land, mostly undeveloped, which is a vast landscape park, full of open meadows, gardens, canals, ponds, groves, and golf courses. In this landscape, nine compact housing complexes were freely placed, reminiscent in the form of fortified castles, and one larger - "a fortress", posed on a defensive town. The architecture of individual units was developed by various architects - including Rob Krier. The landscape architecture - extremely carefully designed - is the work of Paul van Beek. The individual castles have from 50 to 100 units, the 
fortress - 450 apartments of various types. Distances between the castles are not less than $200 \mathrm{~m}$. The total number is about 1000 units, which gives a density of 6 units/ha. This is an extremely low density. However, it should be taken into account that the area - in accordance with the intention of the authorities of 'sHertogenbosh - was to serve not only as a residential but also as a recreation and sports area for all inhabitants.

The "rurban" direction indicates that urban development does not have to "devour" the natural area, but it can create elements that crystallize the landscape, landmarks, and local activity centers. It is also an economic and functional justification for better development and maintenance of the landscape, and thus its protection. The question arises as to how the scattered, "landscape" urban planning in the Haverleij or Sociopolis types meets the demands of sustainability. The solution of efficient public transport and conditions for pedestrian communication seem to be problematic here. There is also no continuous public space system, typical of a compact city. However, the direction does not claim exclusive rights in urban planning. Vincente Guallart points out that the "rurban" approach is primarily a solution to the problem of peripheral zones. The city in the landscape is an interface between the proper city and the right landscape. It is a deliberately shaped transition zone an alternative to amorphous suburbia. The city-landscape becomes a natural recreation zone for a compact city. In this way, both ideas become complementary. Living in one or the other environment becomes again a matter of choice related to the preferred lifestyle.

\section{High buildings}

The description of contemporary trends would not be complete if it was to ignore the dynamic development of the segment of high-rise residential buildings [11]. They are mainly the domain of metropolises of Asia, the USA, and increasingly also of the centers of large European cities. This development is not conditioned by the influence of urban theories but rather by the pressure of economic factors. High construction creates a completely different urban reality, incomparable to the one we know from a traditional European city. This difference is mainly determined by the intensity of land use and the number of inhabitants in relation to the occupied area. The detachment from the ground level and vertical distribution of the functional program requires a new approach to the problem of streets, greenery, and services. As a rule, these elements are included in the volume capacity of buildings in the form of various "skyways", "skygardens", and other devices designed to compensate for the lack of real urban space. The high-rise residential

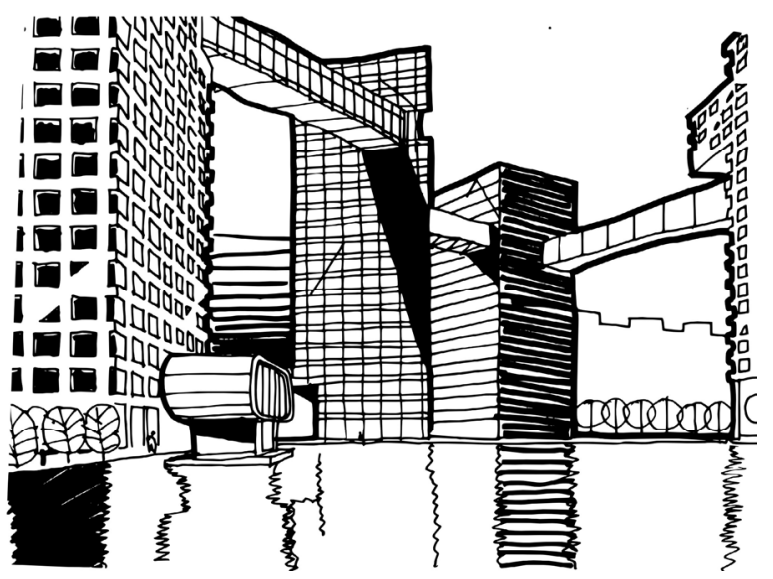

Fig. 11. Linked Hybrid complex by Steven Holl in Beijing (2009). Author's drawing. 
construction of the 21 st century seems to be the new incarnation of utopias from the $1960 \mathrm{~s}$ that finally found favorable economic, technical, and cultural conditions for implementation. However, the question arises as to how much the ambitions of developers and designers coincide in this case with the real needs of inhabitants.

\section{Conclusions}

A characteristic feature of contemporary urban planning is the lack of doctrinal formal assumptions. The formulation of general principles is avoided, and the proposed solutions are of individual nature. The form becomes a means of artistic expression and spatial articulation rather than a carrier of a social idea. It is also a tool for positioning the complex as a product in the market game. It expresses the freedom of choice of the inhabitant as a consumer. The collage city, postulated by Collin Rowe, becomes a reality. At the same time, modern design tools, such as the master plan, counteract the spatial chaos. Particular "molecules" of larger urban complexes, such as Ijburg or Haverleij, gain a common composition frame - a dense street network or a precisely designed landscape. This creates a kind of synergy of pluralism that, as one can anticipate, will become the value of the 21 st-century cities.

\section{References}

1. P. Panerai, J. Castex, J. Depaule, (Urban Forms: The Death and Life of Urban Block,Architectural Press, Oxford, 2004)

2. K. Williams, E. Burton, M. Jenks, Environments by Design 1, 1 (1996)

3. B. Leupen, H. Mooij, Housing Design. A Manual (Nai Publishers, Rotterdam, 2011)

4. E. Firley E., C. Stahl, (The Urban Housing Handbook, John Wiley and Sons, Chichester, 2013)

5. F. Raith, (Inszenierte Architektur: Wohnungsbau jenseits des Standards (DVA, Stuttgart, 2003)

6. http://oma.eu/projects/almere-masterplan (access 2018-04-10)

7. W. Januszewski, J. Latka, (Habitaty-reaktywacja matych społeczności lokalnych (in: Z. Bac (Ed.) Oficyna Wydawnicza Politechniki Wrocławskiej,77-96, 2016)

8. https://www.mvrdv.nl/projects/markethall/ (access 2018-04-10)

9. K. Chwalibog, (Ewolucja struktury zespołów mieszkaniowych, Panstwowe Wydawnictwo Naukowe, Warszawa, 1976)

10. http://www.guallart.com/projects/sociopolis (access 2018-04-10)

11. P. Fernandez, J. Mozas, (Why density ?, A + T Architecture Publishers, Vitoria-Gasteiz, 2015) 